\title{
Companies' InVESTMent Determinants: CoMparison of Different Panel Data Estimators ${ }^{1}$
}

\author{
Zelia Serrasqueiro
}

Departamento de Gestão e Economia, Universidade da Beira Interior, Portugal and CEFAGE (Centro de Estudos e Formação Avançada em Gestão e Economia), Universidade de Évora

\author{
Silvia Mendes \\ Escola Superior de Tecnologia e Gestão de Oliveira do Hospital, \\ Instituto Politécnico de Coimbra, Portugal \\ Paulo Maçãs Nunes \\ Departamento de Gestão e Economia, Universidade da Beira Interior, Portugal
}

\begin{abstract}
In this study, Aivazian, Ge and Qiu's (2005) analysis using static panel models is extended to using dynamic panel estimators, considering data for listed Portuguese companies. The results confirm Aivazian et al.'s (2005) conclusion that an Ordinary Least Squares (OLS) regression is not the best way to estimate the investment/determinant relationship. Investment decisions are probably dynamic, so the most suitable way to estimate the investment/determinant(s) relationship is using dynamic panel estimators. Alternatively a fixed effect panel model can be used, consistent with a first order autocorrelation. In this way, firstly, it is possible to determine more accurately the positive impact of sales (Neo-classic theory) and cash flow (Free Cash Flow theory) on the investments of listed Portuguese companies. Secondly, the positive effect of growth opportunities (Agency theory) is not overestimated when it seems to be the consequence of a first order autocorrelation. Using dynamic panel estimators permits correct measurement of dynamism in company investment decisions by examining the relationship between investment in the previous and the current periods.
\end{abstract}

Keywords: Dynamic Panel Estimators; Investment; Static Panel Models.

JEL C23, G31, G32

\section{1}

\section{Introduction}

Modigliani and Miller (1958) postulated that, provided that there is perfect information and that there are no transaction costs, external and internal finance are perfect substitutes. This implies that investment decisions are independent of companies' financial decisions. However, there are a number of reasons why capital markets are not perfect, namely the existence of taxes, transaction costs and information asymmetry. If markets are characterised by imperfections, investment finance may only be available in capital market with higher costs for companies. This implies that the investment spending of some companies may be constrained by a shortage of internal funds. As a result, the level of internal funding could be an important determinant of corporate investment.

Neo-classic authors, followers of Modigliani and Miller (1958), consider sales to be a fundamental variable in explaining company investment. If sales increase, companies increase their investment levels; but when sales diminish, companies reduce their investment levels. For Neo-classic authors, investment decisions depend essentially on factors outside the company; and sales is a central variable in explaining company investment (Eisner, 1963; Hall \& Jorgenson, 1967; Chirinko, 1993). 
Later, Fazzari, Glenn, Hubbard and Bruce (1988) and Fazzari and Peterson (1993) concluded that the existence of any information asymmetry in the relationship between shareholders/ managers and creditors has consequences for companies that want to access external finance. These authors showed that companies that are financially constrained in terms of their debt capacity tend to use internal finance to a greater extent, measured by company cash flow, to finance their investment than companies that are not constrained in this way. The relevance of cash flow as a debt determinant was the origin of Free Cash Flow theory.

According to the Agency theory, based on the existence of an information asymmetry in relationships between shareholders/managers and creditors on the one hand, and between managers and shareholders on the other, debt should be considered a central variable in explaining company investment.

Myers (1977) and Zwiebel (1996) concluded that one can expect a negative relationship between company debt and a company's level of investment, given that creditors make it more difficult to obtain debt in situations of greater information asymmetry concerning the profitability and risk of projects: finance is only channelled to projects of greater profitability and less risk.

Grossman and Hart (1982), Jensen (1986) and Stulz (1990) concluded that one can expect shareholders to have a preference for debt when shareholders want to discipline managers' actions, so that managers do not invest in projects that make the company grow beyond the optimal level and that can have a negative present net value, harming the company's financial performance.

McConnell and Servaes (1995), Lang, Ofek and Stulz (1996) and Aivazian, Ge and Qiu (2005) concluded that investment is negatively related to debt. These authors argue that debt is used above all as a form of discipline in companies with low growth opportunities, so that managers (who are better informed about companies' specific characteristics) do not invest in projects that could contribute to diminished financial performance.
Aivazian et al. (2005) studied the investment determinants of listed Canadian companies, considering five possible determinants:

- sales;

- cash flow;

- debt;

- growth opportunities; and

- a dummy variable multiplied by the debt, which has the value of 0 when growth opportunities are low, corresponding to situations where the Tobin's q ratio is less than 1 , and the value of 1 when companies have high growth opportunities, corresponding to situations where the Tobin's q ratio is above 1 .

Through the variables mentioned above, Aivazian et al. (2005) tested the various explanatory theories of company investment decisions for listed Canadian companies. They used sales and cash flow in order to test the Neo-classic and Free Cash Flow Theories respectively, and used the remaining variables to test the Agency theory.

Aivazian et al. (2005) concluded that the estimations of investment determinants carried out by McConnell and Servaes (1995) and Lang et al. (1996) ${ }^{2}$ using Ordinary Least Squares (OLS) regressions did not consider the relevance of companies' non-observable individual effects. Aivazian et al. $(2005)^{3}$ argued that the most correct way to estimate the relationship between investment and its determinants is to use a random or fixed effect panel model. They argued that the use of an OLS regression can lead to an underestimation of the impact of explanatory variables on investment, because using this form of estimation implies a failure to consider company heterogeneity, which is measured by companies' non-observable individual effects. The results Aivazian et al. (2005) obtained from using an OLS regression showed that its use would make sales and cash flow irrelevant as determinants of the investment decisions of listed Canadian companies. The same did not happen when they estimated the relationship between investment determinants and listed Canadian company investments using a random or fixed effect panel model. 
Aivazian et al.'s (2005) findings suggest that the results obtained in an investigation may depend on the methodology used for the purpose. This consideration is particularly relevant in respect of empirical studies with panel sample data, given the development of the techniques used, namely the growing use of dynamic estimators.

The rationale for this study, in view of the possibly dynamic nature of company investment decisions, was to extend the analysis done by Aivazian et al. (2005) beyond the use of static panel models to the use of dynamic estimators. We intended to discover whether or not the use of dynamic estimators leads to results that differ from those obtained from the application of static panel models, specifically in terms of the magnitude and statistical significance of the estimated parameters.

The model for estimation used in this study, considering Portuguese listed companies, was similar to that used by Aivazian et al. (2005). The results obtained in this study allowed us to reach two conclusions. The first was that in using static panel models, the most correct way to estimate the relationship between investment determinants and the investments of listed Portuguese companies was to use a fixed effect panel model. The second conclusion was that, where a first order autocorrelation exists, illustrating the relevance of investment in the previous period as a determinant of investment in the current period, the most correct way to estimate the relationship between investment determinants and investment by listed Portuguese companies was to use dynamic panel estimators; or alternatively, to use a fixed effect panel model consistent with the existence of first order autocorrelation. The use of dynamic estimators had the advantage of allowing accurate measurement of the relationship between investment in the previous period and investment in the current period.

To reach the aim of this study, following on from this introduction, the study is divided as follows: the database and methodology are set out in Section 2; the results obtained from this study are presented in Section 3; and finally, the conclusions are discussed in Section 4.

\section{2 \\ Database and methodology}

\subsection{Database}

We used the Finibolsa database for data on listed Portuguese companies. This database provides the balance sheets and income statements of listed Portuguese companies. The number of companies listed on the official stock market is relatively low. We removed four financial companies and two football clubs from the total number of listed companies, leaving 38 companies for which the necessary data was available for the period from 1998 to 2004 . Since not all companies were part of the Portuguese stock market in 1998, the panel that was obtained was not uniform. We used the financial information we considered relevant from companies' income statements and balance sheets.

\subsection{Methodology}

In this section, the methodology used in this study concerning the static panel models and dynamic estimators used is presented.

\subsubsection{Static panel models}

First, we present the results obtained by using static panel models. As already mentioned, the model for estimation is similar to that used by Aivazian et al. (2005). The formula that was used was the following:

$$
\begin{aligned}
& \frac{I_{i, t}}{K_{i, t-1}}=\lambda+\beta_{1} \frac{\text { Sales }_{i, t-1}}{K_{i, t-2}}+\beta_{2} \frac{C F_{i, t}}{K_{i, t-1}}+\beta_{3} \text { Lev }_{i, t-1}+\beta_{4} \text { GOP }_{i, t-1}+; \\
& +\beta_{5} D_{i, t-1} \times \text { Lev }_{i, t-1}+d_{t}+v_{i}+e_{i, t}
\end{aligned}
$$

in which:

$I_{i, t}$ is the net investment given by the variation of fixed capital less depreciations;

$K_{i,-1}$ is the net fixed capital in the previous period, given by the fixed capital less depreciations; 
Sales $_{i, t-1}$ is the sales in the previous period;

$K_{i,-2}$ is the net fixed capital lagged two periods;

$C F_{i, t}$ is the cash flow in the current period given by earnings before extraordinary results plus depreciations;

$L e v_{i, t-1}$ is debt in the previous period given by the ratio of Total Liabilities to Total Assets;

$G O P_{i, t-1}$ are growth opportunities in the previous period, measured by the Tobin's q ratio, in other words, the quotient between the market value of equity plus the book value of assets less the book value of equity and book value of assets;

$D_{i, t-1}$ is the dummy variable in the previous period measuring the impact of the level of the company's growth opportunities on investment, which has the value of 0 when growth opportunities are low, and the value of 1 when growth opportunities are high;

$d_{t}$ are annual dummy variables measuring the impact of macro-economic variables on investment;

$v_{i}$ are non-observable individual effects; and finally

$e_{i, t}$ is the random error presumed to have normal distribution.

To test the relevance of non-observable individual effects, assuming their non-correlation with the explanatory variables, we used the Lagrange Multiplier (LM) test. The null hypothesis indicates the irrelevance of non-observable individual effects. To test the relevance of nonobservable individual effects, assuming their correlation with the explanatory variables, we used the Hausman test. The null hypothesis indicates the irrelevance of non-observable individual effects. Where the null hypotheses of the LM and Hausman tests are not rejected, an OLS regression is the most suitable way to estimate the relationship between investment and its determinants. Where the null hypothesis of the Hausman test is rejected, the most correct way to estimate the relationship between investment and its determinants is using a fixed effect panel model. In any other circumstances, the most correct estimation method is to use a random effect panel model.

In estimations we presented the results of the first and second order autocorrelation tests for the most suitable method of estimating the relationship between determinants and listed Portuguese company investment. We tested the null hypothesis of non-existence of autocorrelation against the alternative hypothesis of existence of autocorrelation.

\subsubsection{Dynamic estimators}

We went on to estimate the relationship between investment and its determinants by turning to dynamic estimators. In considering the use of dynamic estimators, we used the following model:

$$
\begin{aligned}
& \frac{I_{i, t}}{K_{i, t-1}}=\lambda+\alpha \frac{I_{i, t-1}}{K_{i, t-2}}+\beta_{1} \frac{\text { Sales }_{i, t-1}}{K_{i, t-2}}+\beta_{2} \frac{C F_{i, t}}{K_{i, t-1}}+\beta_{3} \text { Lev }_{i, t-1}+; \\
& +\beta_{4} G O P_{i, t-1}+\beta_{5} D_{i, t-1} \times \text { Lev }_{i, t-1}+d_{t}+v_{i}+e_{i, t}
\end{aligned}
$$

Estimating Equation (2) with static panel models. Considering fixed or random nonobservable individual effects, we obtained biased and inconsistent estimates of the parameters, since there was not only a correlation between $v_{i}$ and $\frac{I_{i, t-1}}{K_{i, t-2}}$, but there was also a correlation between $e_{i, t}$ and $\frac{I_{i, t-1}}{K_{i, t-2}}$, that is, companies' nonobservable individual effects. The error was correlated with the lagged investment.

Arellano and Bond (1991) proposed the estimation of Equation (2) in first differences, and the use of the lagged dependent and independent variables in levels as instruments. This estimator became known as the GMM dynamic estimator (Arellano \& Bond, 1991).

However, the results obtained from Arellano and Bond's (1991) GMM dynamic estimator can only be considered valid on two conditions: firstly, the restrictions created by the use of the instruments must be valid; and, secondly, there can be no second order autocorrelation.

In order to test the validity of the restrictions, we used the Sargan test. The null hypothesis 
indicates that the restrictions imposed by the use of the instruments are valid. If we reject the null hypothesis, we must conclude that Arellano and Bond's (1991) GMM dynamic estimator results cannot be considered valid. With regard to second order autocorrelation, the null hypothesis is the non-existence of autocorrelation. If we reject the null hypothesis, we must conclude that the results of Arellano and Bond's (1991) GMM dynamic estimator cannot be considered valid.

Taking advantage of fairly recent developments in dynamic estimators, we investigated the Least Square Dummy Variable Corrected (LSDVC) dynamic estimator proposed by Bruno (2005). Bruno (2005) concluded that in cases where the number of observations is not very high, given the high number of instruments created compared to the number of observations, the use of dynamic estimators can lead to biased estimates of the parameters. Given the rather low number of observations in this study, we examined the results of Bruno's (2005) LSDVC dynamic estimator in order to test the robustness of the results obtained with Arellano and Bond's (1991) GMM dynamic estimator.

\section{3}

\section{Results}

\subsection{Descriptive statistics and correlation matrix}

Tables A1 and A2 in Appendix A show the descriptive statistics of the variables and the respective correlation matrices.
We found that investment is a volatile behavioural phenomenon, and that the standard deviation was considerably above the mean: the mean was close to zero, but the standard deviation was 0.46 .

The cash flow and growth opportunities variables also displayed some volatility. Again, the respective standard deviations were above the mean. Although the volatility of the cash flow and growth opportunities was variable, these factors were less volatile than investment. The sales and debt variables did not display great volatility, and the standard deviations were lower than the respective means.

We noted that the correlation coefficient between investment in the current period and investment in the previous period was positive, and statistically significant at a 5 per cent level of significance, indicating that investment followed a continuous dynamic process. However, the correlation between investment in the current period and investment in the previous period was not very pronounced, indicating that investment cannot be considered a persistent series, and that it may be most appropriate to use Arellano and Bond's (1991) GMM dynamic estimator. ${ }^{4}$

The correlation coefficients between the explanatory variables of investment were not too high. These results indicated that collinearity between explanatory variables may not be relevant in this study.

\subsection{Static panel models}

Next, we present the results of the static panel models. The results are shown in the following table.

\section{Table 1}

Static panel models

\begin{tabular}{|c|c|c|c|c|c|}
\hline \multicolumn{7}{|c|}{ Dependent variable: $\frac{I_{i, t}}{K_{i, t-1}}$} \\
\hline $\begin{array}{c}\text { Independent } \\
\text { variables }\end{array}$ & Pooled effects & $\begin{array}{c}\text { Random } \\
\text { effects }\end{array}$ & Fixed effects & $\begin{array}{c}\text { Random } \\
\text { effects AR (1) }\end{array}$ & $\begin{array}{c}\text { Fixed effects } \\
\text { AR (1) }\end{array}$ \\
\hline$\frac{\text { Sales }}{K_{i, t-1}}$ & $\begin{array}{c}-0.0197 \\
(0.0193)\end{array}$ & $\begin{array}{c}-0.0189 \\
(0.0199)\end{array}$ & $\begin{array}{c}0.0942^{*} \\
(0.0499)\end{array}$ & $\begin{array}{c}-0.0126 \\
(0.0252)\end{array}$ & $\begin{array}{c}0.1132^{* *} \\
(0.0535)\end{array}$ \\
\hline$\frac{C F_{i, t}}{K_{i, t-1}}$ & $0.5589^{* * *}$ & $0.5808^{* * *}$ & $1.0792^{* * *}$ & $0.9217^{* * *}$ & $1.7558^{* * *}$ \\
& $(0.1682)$ & $(0.1694)$ & $(0.2073)$ & $(0.1823)$ & $(0.2208)$ \\
\hline
\end{tabular}




\begin{tabular}{|c|c|c|c|c|c|}
\hline $\operatorname{Lev}_{i, t-1}$ & $\begin{array}{c}-0.2762 \\
(0.2047)\end{array}$ & $\begin{array}{l}-0.2921 \\
(0.2079)\end{array}$ & $\begin{array}{c}-0.9854 * * * \\
(0.3116)\end{array}$ & $\begin{array}{l}-0.2703 \\
(0.2468)\end{array}$ & $\begin{array}{c}-0.8345^{* *} \\
(0.3456)\end{array}$ \\
\hline$G O P_{i, t-1}$ & $\begin{array}{l}0.1014^{* * *} \\
(0.0190)\end{array}$ & $\begin{array}{l}0.1027^{* * *} \\
(0.0191)\end{array}$ & $\begin{array}{l}0.1284^{* * *} \\
(0.0216)\end{array}$ & $\begin{array}{l}0.1045^{* * *} \\
(0.0192)\end{array}$ & $\begin{array}{c}0.01045 \\
(0.0222)\end{array}$ \\
\hline$D_{i, t-1} \times L e v_{i, t-1}$ & $\begin{array}{l}-0.0483 \\
(0.0833)\end{array}$ & $\begin{array}{l}-0.0458 \\
(0.0839)\end{array}$ & $\begin{array}{c}0.06527 \\
(0.1037)\end{array}$ & $\begin{array}{l}-0.0203 \\
(0.0911)\end{array}$ & $\begin{array}{c}0.11207 \\
(0.0896)\end{array}$ \\
\hline CONS & $\begin{array}{c}0.0175 \\
(0.1483)\end{array}$ & $\begin{array}{c}0.0212 \\
(0.1509)\end{array}$ & $\begin{array}{c}0.1522 \\
(0.2252)\end{array}$ & $\begin{array}{c}-0.0651 \\
(0.1797)\end{array}$ & $\begin{array}{c}0.0529 \\
(0.1641)\end{array}$ \\
\hline Observations & 216 & 216 & 216 & 216 & 178 \\
\hline $\mathrm{R}^{2}$ & 0.1676 & 0.2342 & 0.2869 & 0.2549 & 0.3681 \\
\hline $\mathrm{F}(\mathrm{N}(0,1))$ & $8.46^{* * *}$ & & $13.92^{* * *}$ & & $15.73^{* * *}$ \\
\hline Wald $\left(\chi^{2}\right)$ & & $43.20^{* * *}$ & & $49.73^{* * *}$ & \\
\hline LM test & & 0.17 & & & \\
\hline Hausman test & & $33.72 * * *$ & & & \\
\hline $\mathrm{m} 1(0,1)$ & & & $-3.71 * * *$ & & \\
\hline $\mathrm{m} 2(0,1)$ & & & 0.29 & & \\
\hline
\end{tabular}

\section{Notes:}

1. The LM test has a $\chi^{2}$ distribution and tests the null hypothesis that non-observable individual effects are not relevant in explaining the dependent variable against the alternative hypothesis of relevance of non-observable individual effects in explaining the dependent variable.

2. The Hausman test has a $\chi^{2}$ distribution and tests the null hypothesis that non-observable individual effects are not correlated with the explanatory variables against the null hypothesis of correlation between non-observable individual effects and the explanatory variables.

3. The Wald test has a $\chi^{2}$ distribution and tests the null hypothesis of non-significance as a whole of the parameters of the explanatory variables against the alternative hypothesis of significance as a whole of the parameters of the explanatory variables.

4. The F test has a normal distribution $\mathrm{N}(0.1)$ and tests the null hypothesis of non-significance as a whole of the estimated parameters against the alternative hypothesis of significance as a whole of the estimated parameters.

5. The $\mathrm{m} 1$ test is a test for first order autocorrelation of residuals and is distributed as $\mathrm{N}(0.1)$, under a null hypothesis of no first order autocorrelation.

6. The $\mathrm{m} 2$ test is a test for second order autocorrelation of residuals and is distributed as $\mathrm{N}(0.1)$, under a null hypothesis of no second order autocorrelation.

7. Standard deviations in brackets.

8. *** significant at a 1 per cent level of significance;

** significant at a 5 per cent level of significance;

* significant at a 10 per cent level of significance.

9. Year-dummies are included, in estimation, but are not shown. 
The results of the LM test led us to conclude that we could not reject the null hypothesis of the absence of relevance of companies' nonobservable individual effects, assuming their non-correlation with the explanatory variables.

Nevertheless, observing the results of the Hausman test, we rejected the null hypothesis of the absence of correlation between nonobservable individual effects and the explanatory variables, and so the most suitable way to carry out estimates of the relationship between investment and its determinants was using a fixed effect panel model.

The autocorrelation tests indicated that we had to reject the null hypothesis of the non-existence of first order autocorrelation, but that we should not reject the null hypothesis of the non-existence of second order autocorrelation. The existence of first order autocorrelation can limit some of the empirical relationships established between investment determinants and investments by listed Portuguese companies.

Estimating the results with a fixed effect panel model consistent with the existence of first order autocorrelation, we found firstly, the parameters measuring the impact of sales and cash flow on investment increased considerably - in the case of sales, the parameter became statistically significant at a 5 per cent level of significance; and, secondly, the parameter measuring the relationship between growth opportunities and investment ceased to be statistically significant.

Given the existence of first order autocorrelation, investment in the previous period may assume relevance for the investment decisions of listed Portuguese companies in the current period.

Appendix B presents the results arrived at through the use of static panel models, considering explicitly the relationship between investment in the previous period and investment in the current period, aiming to eliminate the problem of first order autocorrelation. ${ }^{5}$

The problem of the existence of first order autocorrelation was eliminated. However, we observed that only the parameter measuring the relationship between cash flow and investment in listed Portuguese companies was statistically significant.

The statistical insignificance of the parameter measuring the relationship between investment in the previous period and investment in the current period is due to the correlation between $v_{i}$ and $\frac{I_{i, t-1}}{K_{i, t-2}}$ and between $e_{i, t}$ and $\frac{I_{i, t-1}}{K_{i, t-2}}$. However, the correlations between $v_{i}$ and $\frac{K_{i, t-1}}{K_{i, t-2}}$ and between $e_{i, t}$ and $\frac{I_{i, t-1}}{K_{i, t-2}}$ could also affect the estimated parameters measuring relationships between first, sales and investment; second, debt and investment; and third, growth opportunities and investment-parameters that are statistically significant when estimating the relationship between determinants and investment with a fixed effect panel model, without explicitly considering the relationship between investment in the previous period and investment in the current period. ${ }^{6}$

\subsection{Dynamic estimators}

Next we present the results of Arellano and Bond's (1991) GMM and Bruno's (2005) LSDVC dynamic estimators. The results are shown in Table 2. 


\section{Table 2}

Dynamic estimators - GMM (Arellano \& Bond, 1991), GMM system (Blundell \& Bond, 1998) and LSDVC (Bruno, 2005)

\begin{tabular}{|c|c|c|}
\hline \multicolumn{3}{|c|}{ Dependent variable: $\frac{I_{i, t}}{K_{i, t-1}}$} \\
\hline Independent variables & GMM(1991) & $\begin{array}{l}\text { LSDVC (2005) } \\
\qquad \text { I (ab) }\end{array}$ \\
\hline$\frac{I_{i, t-1}}{K_{i, t-2}}$ & $\begin{array}{l}0.2926^{* * *} \\
(0.0725)\end{array}$ & $\begin{array}{l}0.3322^{* * *} \\
(0.0739)\end{array}$ \\
\hline$\frac{\text { Sales }_{i, t-1}}{K_{i, t-2}}$ & $\begin{array}{l}0.2489 * * * \\
(0.0699)\end{array}$ & $\begin{array}{l}0.1160^{* *} \\
(0.0456)\end{array}$ \\
\hline$\frac{C F_{i, t}}{K_{i, t-1}}$ & $\begin{array}{l}2.3375^{* * *} \\
(0.2528)\end{array}$ & $\begin{array}{l}2.0110^{* * *} \\
(0.2648)\end{array}$ \\
\hline $\operatorname{Lev}_{i, t-1}$ & $\begin{array}{l}-0.9532^{* *} \\
(0.4535)\end{array}$ & $\begin{array}{l}-0.8079 * * \\
(0.3381)\end{array}$ \\
\hline$G O P_{i, t-1}$ & $\begin{array}{l}0.0178 \\
(0.0304)\end{array}$ & $\begin{array}{l}0.0061 \\
(0.0306)\end{array}$ \\
\hline$D_{i, t-1} \times \operatorname{Lev}_{i, t-1}$ & $\begin{array}{c}0.0770 \\
(0.1195)\end{array}$ & $\begin{array}{c}0.1108 \\
(0.1113)\end{array}$ \\
\hline CONS & $\begin{array}{l}-0.0029 \\
(0.0232)\end{array}$ & \\
\hline Instruments & GMM & \\
\hline Observations & 141 & \\
\hline Wald $\left(\chi^{2}\right)$ & $114.96^{* * *}$ & \\
\hline Sargan $\chi^{2}$ ) & 13.84 & \\
\hline \multicolumn{3}{|l|}{ Hansen $\left(\chi^{2}\right)$} \\
\hline $\mathrm{m} 1(0,1)$ & $-3.50^{* * *}$ & \\
\hline $\mathrm{m} 2(0,1)$ & 0.66 & \\
\hline
\end{tabular}

\section{Notes:}

1. The instruments are $\left(\frac{I_{i, t-2}}{K_{i, t-3}} ; \frac{\text { Sales }_{i, t-2}}{K_{i, t-3}} ; \frac{C F_{i, t-2}}{K_{i, t-3}}, \operatorname{Lev}_{i, t-2}, G O P_{i, t-2} ; D_{i, t-2} \times L e v_{i, t-2} ; \sum_{t=3}^{6} d_{t}\right)$.

2. The Wald test is a test of the joint significance of the estimated firm specific coefficients. The test is asymptotically distributed as $\chi^{2}$ under the null hypothesis of no relationship.

3. The Sargan test of over-identifying restrictions is asymptotically distributed as $\chi^{2}$ under the null hypothesis of instrument validity, used in the one-step GMM estimation method (Arellano \& Bond, 1991).

4. The $\mathrm{m} 1$ test is a test for first order autocorrelation of residuals and is distributed as $\mathrm{N}(0.1)$, under a null hypothesis of no first order autocorrelation. 
5. The $\mathrm{m} 2$ test is a test for second order autocorrelation of residuals and is distributed as $\mathrm{N}(0.1)$, under a null hypothesis of no second order autocorrelation.

6. Heteroskedasticity consistent and asymptotic robust standard deviations are reported in brackets.

7. *** indicates significance at a 1 per cent level of significance,

** indicates significance at a 5 per cent level of significance, and

* indicates significance at a 10 per cent level of significance.

8. Year-dummies are included in estimation, but are not shown.

The results of the Sargan tests led us to conclude that we could not reject the null hypothesis of the validity of the instruments used and consequent restrictions at a 1 per cent level of statistical significance.

The result of the second order autocorrelation test indicated that we could not reject the null hypothesis of the absence of second order autocorrelation.

Given the validity of the instruments and consequent restrictions, and the absence of second order autocorrelation, we concluded that the results of Arellano and Bond's (1991) GMM dynamic estimator could be considered valid.

To test the robustness of the results obtained from the application of Arellano and Bond's (1991) GMM dynamic estimator, we used Bruno's (2005) LSDVC dynamic estimator, which is appropriate for situations where the number of observations is not very high. The results using Bruno's (2005) LSDVC estimator were consistent with the results using Arellano and Bond's (1991) GMM dynamic estimator, since there was no substantial change in the magnitude of the parameters or in their statistical significance.

\subsection{Static models versus dynamic estimators}

Next we present a summary of the results on the magnitude and statistical significance of the estimated parameters using the static models and dynamic panel estimators. The results are shown in the following table.

Table 3

Summary of the results of applying the various estimators: Empirical evidence for Portugal

\begin{tabular}{|c|c|c|c|c|c|c|c|}
\hline$\frac{I_{i, t}}{K_{i, t-1}}$ & OLS & $\begin{array}{c}\text { Random } \\
\text { effects }\end{array}$ & $\begin{array}{l}\text { Fixed } \\
\text { effects }\end{array}$ & $\begin{array}{c}\text { Random } \\
\text { effects } \\
\text { AR(1) }\end{array}$ & $\begin{array}{l}\text { Fixed } \\
\text { effects } \\
\text { AR(1) }\end{array}$ & $\begin{array}{l}\text { GMM } \\
\text { (1991) }\end{array}$ & $\begin{array}{l}\text { LSDVC } \\
(2005)\end{array}$ \\
\hline$\frac{I_{i, t-1}}{K_{i, t-2}}$ & & & & & & $0.2926(* * *)$ & $0.3322\left(^{* * *}\right)$ \\
\hline$\frac{\text { Sales }_{i, t-1}}{K_{i, t-2}}$ & -0.0197 (n.s.) & -0.0189 (n.s.) & $0.0942\left(^{*}\right)$ & -0.0126 (n.s.) & $0.1132(* *)$ & $\left.0.2489{ }^{* * *}\right)$ & $0.1160\left(^{* * *}\right)$ \\
\hline$\frac{C F_{i, t}}{K_{i, t-1}}$ & $0.5589(* * *)$ & $0.5808\left(^{* * *}\right)$ & $1.0792(* * *)$ & $0.9217\left(^{* * *}\right)$ & $1.7558\left(^{* * *}\right)$ & $2.3375^{(* *)}$ & $\left.2.0110{ }^{* * *}\right)$ \\
\hline $\operatorname{Lev}_{i, t-1}$ & -0.2762 (n.s.) & -0.2921 (n.s.) & $-0.9854(* * *)$ & -0.2703 (n.s.) & $-0.8345(* * *)$ & $-0.9532(* *)$ & $-0.8079\left(^{* *}\right)$ \\
\hline$G O P_{i, t-1}$ & $0.1014(* * *)$ & $\left.0.1027^{* * *}\right)$ & $0.1284(* * *)$ & $0.1045(* * *)$ & 0.0104 (n.s.) & 0.0178 (n.s.) & 0.0061 (n.s.) \\
\hline$D_{i, t-1} \times \operatorname{Lev}_{i, t-1}$ & -0.0483 (n.s.) & -0.0458 (n.s.) & 0.0652(n.s.) & -0.0203 (n.s.) & 0.1120 (n.s.) & 0.0770 (n.s.) & 0.1108 (n.s.) \\
\hline
\end{tabular}




\section{Notes:}

1. n.s. not significant.

2. $* * *$ significant at a 1 per cent level of significance.

3. ** significant at a 5 per cent level of significance.

4. * significant at a 10 per cent level of significance.

With regard to the application of static panel models, we could see that the results obtained from a fixed effect panel model differed considerably from those obtained from an OLS regression or from a random effect panel model. There was some similarity between the results obtained using an OLS regression and a random effect panel model. The results obtained are in agreement with the results using the LM and Hausman ${ }^{7}$ tests.

With an OLS regression and a random effect panel model, the relationships between cash flow and investment and between growth opportunities and investment were positive and statistically significant. However, with a fixed effect panel model, in addition to the positive and statistically significant relationships between cash flow and investment and between growth opportunities and investment, we found a negative and statistically significant relationship between debt and investment and a positive relationship (statistically significant at a 10 per cent level of significance) between sales and investment. ${ }^{8}$

Observing the estimated parameters, we found that when we used an OLS regression and a random effect panel model, the positive impact of cash flow and growth opportunities on investment was underestimated, compared to the impact found when using a fixed effect panel model. ${ }^{9}$

The results of the autocorrelation tests showed the existence of first order autocorrelation, which may imply bias of some of the estimated parameters measuring the relationship between the investment determinants and investment by listed Portuguese companies.

When we estimated the relationship between investment and its determinants using a fixed effect panel model, assuming the existence of first order autocorrelation, the results were different, ${ }^{10}$ particularly concerning the effects of sales, cash flow and growth opportunities on investment. In the first place, the impact of sales on investment became more significant, with regard to the magnitude of the estimated parameter and its statistical significance (becoming statistically significant at a 5 per cent level of significance). In the second place, with regard to the magnitude of the estimated parameter, the impact of cash flow on investment became considerably more significant. In the third place, the estimated parameter measuring the impact of growth opportunities on investment ceased to be statistically significant.

Estimating the relationship between investment and its determinants using Arellano and Bond's (1991) GMM and Bruno's (2005) LSDVC dynamic estimators, and with a fixed effect panel model, assuming the existence of first order autocorrelation, we found considerable similarities:

- the parameter measuring the relationship between sales and investment was positive and statistically significant at a 1 per cent level of significance, using Arellano and Bond's (1991) GMM and Bruno's (2005) LSDVC dynamic estimators, and statistically significant at a 5 per cent level of significance, using a fixed effect panel model assuming the existence of first order autocorrelation;

- the parameter measuring the impact of cash flow on investment was positive and statistically significant at a 1 per cent level of significance, in all cases;

- the parameter measuring the relationship between debt and investment was negative and statistically significant at a 1 per cent level of significance, using a fixed effect panel model assuming the existence of first order autocorrelation, and statistically significant at a 5 per cent level of significance using Arellano and Bond's (1991) GMM 
and Bruno's (2005) LSDVC dynamic estimators;

- the parameter measuring the relationship between growth opportunities and investment was, in all cases, statistically insignificant; and

- the parameter measuring the impact of the dummy variable, according to the level of growth opportunities on investment, was, in all cases, statistically insignificant.

Concerning the magnitude of the estimated parameters, it is clear that the impact of cash flow, sales and debt on investment were greater when we estimated the relationship between investment and its determinants using Arellano and Bond's (1991) GMM dynamic estimator, compared to using Bruno's (2005) LSDVC dynamic estimator and a fixed effect panel model consistent with the existence of first order autocorrelation.
Although the results obtained with dynamic panel estimators and a fixed effect panel model consistent with the existence of first order autocorrelation did not lead to very different results with regard to the magnitude and statistical significance of the estimated parameters measuring the relationship between the determinants and listed Portuguese company investment, the use of dynamic estimators has the added advantage of allowing accurate measurement of the impact of investment in the previous period on company investment decisions in the current period.

\subsection{Influence of estimation method on validation of theories}

The Table 4 below presents the results of comparing the relationships forecast by the Neoclassic, Free Cash Flow and Agency theories about the determinants of company investment already presented in the introduction to this study, with the empirical evidence obtained in the context of listed Portuguese companies.

\section{Table 4}

Expected signals and empirical results of applying the various estimators: empirical evidence for Portugal

\begin{tabular}{|c|c|c|c|c|c|}
\hline$\frac{\boldsymbol{I}_{i, t}}{\boldsymbol{K}_{i, t-1}}$ & Expected signal & $\begin{array}{l}\text { OLS and } \\
\text { random effects }\end{array}$ & Fixed effects & $\begin{array}{c}\text { Fixed effects } \\
\qquad A R(1)\end{array}$ & $\begin{array}{l}\text { Dynamic } \\
\text { estimators }\end{array}$ \\
\hline$\frac{\text { Sales }_{i, t-1}}{K_{i, t-2}}$ & $\begin{array}{c}+(\mathrm{Neo}-\text { classic } \\
\text { theory })\end{array}$ & $+($ n.s. $)$ & $+\left({ }^{*}\right)$ & $+(* *)$ & $+(* * *)$ \\
\hline$\frac{C F_{i, t}}{K_{i, t-1}}$ & $\begin{array}{l}+ \text { (Free cash } \\
\text { flows theory) }\end{array}$ & $+(* * *)$ & $+(* * *)$ & $+(* * *)$ & $+(* * *)$ \\
\hline $\operatorname{Lev}_{i, t-1}$ & $\begin{array}{l}\text { - (Agency } \\
\text { theory) }\end{array}$ & $-($ n.s. $)$ & $-(* * *)$ & $-(* * *)$ & $-(* *)$ \\
\hline$G O P_{i, t-1}$ & $\begin{array}{l}+ \text { (Agency } \\
\text { theory) }\end{array}$ & $+(* * *)$ & + (n.s.) & + (n.s.) & + (n.s.) \\
\hline$D_{i, t-1} \times \operatorname{Lev}_{i, t-1}$ & $\begin{array}{l}+ \text { (Agency } \\
\text { theory) }\end{array}$ & - (n.s.) & $+($ n.s. $)$ & + (n.s.) & $+($ n.s. $)$ \\
\hline
\end{tabular}

\section{Notes:}

1. n.s. not significant.

2. $* * *$ significant at a 1 per cent level of significance.

3. ** significant at a 5 per cent level of significance.

4. * significant at a 10 per cent level of significance. 
Estimating the relationship between the determinants and investment by listed Portuguese companies by means of an OLS regression or a random effect panel model would lead to the rejection of the positive relationship between sales and investment forecast by the Neo-classic theory. With regard to listed Canadian companies, Aivazian et al. (2005) obtained a statistically insignificant relationship between sales and investment when using an OLS regression, but obtained a positive and statistically significant relationship using a random or fixed effect panel model. For listed American companies, McConnell and Servaes (1995) and Lang et al. (1996), using only OLS regressions, found a positive and statistically significant relationship between sales and investment.

For listed Portuguese companies, estimating the relationship between the determinants of investment and investment without using dynamic panel estimators, or alternatively without considering the existence of first order autocorrelation, when using a fixed effect panel model, would lead to an underestimation of the impact of sales on investment, with regard to the magnitude and statistical significance of the estimated parameter.

Consideration of the dynamic character of investment decisions using either dynamic estimators or a fixed effect panel model consistent with the existence of first order autocorrelation led to a correct evaluation of the impact of sales on investment by listed Portuguese companies. The results suggest that there is a significant variation of investment, in the same direction as sales variation, corroborating what the $\mathrm{NeO}$ classic theory forecast (Eisner, 1963; Hall \& Jorgenson, 1967; Chirinko, 1993).

It must be noted that the relevance of sales in the context of company investment decisions was also affirmed by De Wet and Hall (2006), who concluded that sales have a positive impact on cash flow, contributing to the possibility of company growth, requiring less recourse to external finance in order to finance investment.

Irrespective of which estimator was used and of whether or not the existence of first order autocorrelation was taken into account, the empirical evidence from the current study shows a positive and statistically significant relationship between cash flow and investment by listed Portuguese companies. Therefore, we can conclude that a higher level of cash flow in listed Portuguese companies is a determinant factor for increased investment. This result agrees with that forecast theoretically by the Free Cash Flow theory (Fazzari et al., 1988; Fazzari \& Peterson, 1993). Consequently, information asymmetry in the relationships between shareholders/managers and creditors seems to have special relevance in listed Portuguese companies' access to external finance, internal finance being fundamental as a basic source of investment finance.

Various empirical studies show a positive and statistically significant relationship between cash flow and company investment (Schaller, 1993; Hubbard, Glen \& Whited, 1995; Cleary, 1999; Vermeulen, 2002; McConnell \& Servaes, 1995; Lang et al., 1996; Aivazian et al. 2005). However, Aivazian et al. (2005) only found a positive and statistically significant relationship between cash flow and investment when estimating the relationship between determinants and investment using a random or fixed effect panel model, and the estimated parameter was not statistically significant when using an OLS regression.

With regard to the statistical significance of the estimated parameter measuring the relationship between cash flow and investment, the use of different estimators did not affect the results that were obtained. Nevertheless, the positive relationship between cash flow and investment can be measured more accurately with dynamic panel estimators, or alternatively with a fixed effect panel model, consistent with the existence of first order autocorrelation. When the process was not done in this way, there tended to be an underestimation of the effect of cash flow on investments by listed Portuguese companies in terms of the magnitude of the estimated parameter.

In respect of listed American companies, McConnell and Servaes (1995) and Lang et al. (1996), and in respect of listed Canadian companies, Aivazian et al. (2005) found a negative relationship between debt and 
investment using OLS regressions. Aivazian et al. (2005) also found a negative and statistically significant relationship when using random or fixed effect panel models.

Estimating the relationship between the determinants and the investments of listed Portuguese companies by using an OLS regression or with a random effect panel model, we obtained a statistically insignificant relationship between debt and investment, which means that we would consider the effect of debt on the investment decisions of listed Portuguese companies negligible, when in fact that effect is considerable.

The results obtained with a fixed effect panel model or with dynamic panel models indicated that a greater level of debt means reduced investment by listed Portuguese companies. The results validated the theoretical arguments of the Agency theory, namely that in the presence of problems of information asymmetry, creditors make access to debt difficult, and so companies have to channel investment only to the most profitable and to less risky projects (Myers, 1977; Zwiebel, 1996). In this context, the study by Pretorius and Shaw (2004) is particularly relevant, because those authors concluded that information asymmetry in the relationship between shareholders and creditors limits access to debt by South African companies in a risky business.

The relationship between growth opportunities and investment by listed Portuguese companies also depends on the method used for estimating the relationship between the determinants and investment. When we used only dynamic panel estimators, or alternatively a fixed effect panel model consistent with the existence of first order autocorrelation, the relationship between growth opportunities and investment by listed Portuguese companies was not statistically significant. If we did not consider the dynamism in the investment decisions of listed Portuguese companies, we had to corroborate the theoretical argument proposed by the Agency theory that growth opportunities are a relevant factor in companies' investment decisions (Grossman \& Hart, 1982; Jensen, 1986; Stulz, 1990) when, in fact, that result seems to be a consequence of the existence of first order autocorrelation.
McConnell and Servaes (1995) and Lang et al. (1996) used OLS regressions for listed American companies, and found a positive and statistically significant relationship between growth opportunities and investment. ${ }^{11}$ Aivazian et al. (2005) obtained the same result for listed Canadian companies using OLS regressions, as well as random and fixed effect panel models. Contrary to the results Aivazian et al. (2005) obtained in the context of listed Canadian companies, the current study suggests that the relationship between growth opportunities and investment by listed Portuguese companies depends on the estimation method used.

From the results obtained for the relationship between the dummy variable measuring the impact of debt, according to level of growth opportunities ( 1 is high, 0 is low) and investment by listed Portuguese companies, we concluded that whatever the estimation method used, the relationship is always statistically insignificant.

The empirical evidence obtained in this study did not support the theoretical arguments of the Agency theory, namely that debt is used by shareholders in order to discipline managers' actions, especially in firms with low growth opportunities (Grossman \& Hart, 1982; Jensen, 1986; Stulz, 1990).

The relationship between debt and investment did not seem to depend on the level of growth opportunities available to listed Portuguese companies. This result contradicts the findings of Lang et al. (1996) and Aivazian et al. (2005) for listed American and Canadian companies respectively, as those authors identified a negative relationship between debt and investment in companies with low growth opportunities. ${ }^{12}$

\section{4}

\section{Conclusion}

Aivazian et al. (2005) concluded that OLS regressions may not be the most correct way to estimate the relationship between determinants of investment and actual investment, because OLS regressions do not take into consideration the possible heterogeneity of companies, which is measured by non-observable individual effects through recourse to random or fixed effect 
panel models. Aivazian et al.'s (2005) results suggest that there is a possibility that the results obtained in such a study depend on the method of estimation used.

In this study, our aim was to extend the analysis carried out by Aivazian et al. (2005), who used static panel models, by using dynamic estimators, considering data on listed Portuguese companies.

With regard to the use of static panel models without assuming the existence of first order autocorrelation, it was clear that the results obtained from using a fixed effect panel model were different from those obtained using an OLS regression or a random effect panel model. This finding differs from the results obtained by Aivazian et al. (2005), whose results were similar, irrespective of whether they used a random or a fixed effect panel model.

However, the existence of first order autocorrelation implies that there is bias due to some of the estimated parameters measuring the relationship between the determinants of investment and the actual investment by listed Portuguese companies. When we estimated the relationship between investment and its determinants using a fixed effect panel model, assuming the existence of first order autocorrelation, we found a change in some of the estimated parameters in respect of their magnitude and statistical significance. This result is indicative of the need to consider in the model that is used what the impact of investment in the previous period is for investment in the current period. This means that it is advisable to consider the possible dynamism in companies' investment decisions when estimating the relationship between investment and its determinants. The fact that we obtained similar results using dynamic estimators and a fixed effect panel model assuming the existence of first order autocorrelation confirms that need.

The results of the Sargan and second order autocorrelation tests confirmed the robustness of the results obtained using Arellano and Bond's (1991) GMM dynamic estimator. The positive relationship between investment in the previous period and investment in the current period, which was statistically significant at a 1 per cent level of significance, reinforces the relevance of using dynamic estimators in studying investment determinants.

The results obtained in this study confirm the conclusion of Aivazian et al. (2005) that an OLS regression is not the most correct way to estimate the relationship between investment and its determinants.

In the current study using static panel models, the most correct way to estimate the relationship between the determinants of investment and actual investment is the use of a fixed effect panel model. However, because the existence of first order autocorrelation indicates the possibility that investment decisions are dynamic, we would argue that the most appropriate way to estimate the relationship between investment and the determinants of investment is to use dynamic panel estimators, or alternatively a fixed effect panel model, but one that is of necessity consistent with the existence of first order autocorrelation. If we do not proceed in this way, we would be underestimating the impact of cash flow and sales on investment. With regard to sales, in addition to the magnitude of the estimated parameter, we would also underestimate its statistical significance. Therefore we could conclude that growth opportunities were relevant when this result appears to be a consequence of the existence of first order autocorrelation, because, when we used dynamic estimators or a fixed effect panel model consistent with the existence of first order autocorrelation, we did not obtain that result.

Through the use of dynamic panel estimators, or alternatively through the use of a fixed effect panel model consistent with the existence of first order autocorrelation, we neither devalue the Neo-classic and Free Cash flow theories as theories that could explain the investments made by listed Portuguese companies, nor overvalue Agency theory concerning the positive effect of growth opportunities on investment.

To summarise, we found that in order to determine the relationship between investment and its determinants, the use of dynamic estimators is more advisable than the use of static panel models, because by proceeding in this way we could consider the possible dynamism of companies' investment decisions. The results obtained in this study suggest that 
when investigators choose to use static panel models, they should consider the possible influence of autocorrelation on the results obtained. The use of dynamic panel estimators has the added advantage of allowing accurate measurement of the effect of investment in the previous period on investment decisions in the current period.

\section{End Notes}

1 The authors would like to acknowledge the helpful comments of the anonymous reviewers and of the South African Journal of Economics and Management Sciences Editor, all of which have substantially improved the article.

2 The studies by McConnell and Servaes (1995) and Lang et al. (1996) refer to the USA, and are based on companies listed on the Stock Exchange.

3 The study by Aivazian et al. (2005) is based on Canadian companies listed on the Stock Exchange.

4 Blundell and Bond (1998) conclude that when the dependent variable is persistent - that is, there is high correlation between its values in the current and previous periods (the number of cross-sections is not very high), the GMM estimator (Arellano \& Bond, 1991) can be inefficient, given the possibility that the instruments that are created may be weak. Blundell and Bond extended Arellano and Bond's (1991) GMM estimator, considering a system with variables at different levels and in first differences. For the variables at different levels, the instruments are presented in first differences, while for the variables in first differences the instruments are presented at different levels. The estimator presented by Blundell and Bond (1998) became known as the GMM system estimator (Blundell \& Bond, 1998). However, because the GMM system estimator (Blundell \& Bond, 1998) generates a very high number of instruments its use is not advised in situations where the number of observations is not particularly high. Due to the fact that no particular persistence of the investment was found, and the fact that the number of observations was not very high, in this study we chose to apply the original GMM estimator (Arellano \& Bond, 1991), a choice which was shown to be suitable given the validity of the instruments generated.

5 Results of the LM and Hausman tests led us to conclude that the most correct way to estimate relationships between determinants and investment continues to be a fixed effect panel model. This result is identical to the one obtained when the relationship between investment in the previous period and investment in the current period was not considered explicitly.

6 This is so although the parameter that measures the relationship between sales and investment is statistically significant at a 10 per cent level of significance.

7 The result of the LM test indicates that it does not matter whether one carries out an estimation of investment determinants using an OLS regression or using a random effect panel model. However, the result of the Hausman test indicates there is correlation between non-observable individual effects and the independent variables, and so the most correct way to estimate the relationship between an investment and its determinants is using a fixed effect panel model.

8 Unlike the results obtained in this study, Aivazian et al. (2005) obtained quite similar results for listed Canadian companies between estimations using random and fixed effect panel models. The results were different when they estimated the relationship between an investment and its determinants using an OLS regression. Using a fixed and random effect panel model, Aivazian et al. (2005) found that there was a positive and statistically significant impact from cash flow, sales, growth opportunities and the dummy variable on investment, and found that there was a negative and statistically significant relationship between debt and investment. Using an OLS regression, the relationships between cash flow and investment and between sales and investment are not statistically significant.

9 Concerning the magnitude of the estimated parameters, the results obtained by Aivazian et al. (2005) show that the impact of debt on investment and growth opportunities on investment tends to be underestimated when an OLS regression is used, compared to the impact estimated when fixed and random effect panel models are used. In their study, the Hausman test indicated the existence of a correlation between companies' nonobservable individual effects and investment. The results obtained by using a random and fixed effect model were quite similar concerning the statistical significance and magnitude of the estimated parameters. By contrast, in this study, the results obtained show the existence of considerable differences between the application of a random or fixed panel model with regard to the statistical significance and magnitude of the estimated parameters. 
10 It should also be pointed out that the value of $R^{2}$ increases quite noticeably when we estimated the relationship between an investment and its determinants using a fixed effect panel model, assuming the existence of first order autocorrelation.

11 Nayager and Van Vuuren (2005) concluded that when large companies take advantage of high growth business opportunities, this can contribute to greater diversification and consequently to company growth, allowing such companies to become more profitable.

12 These authors justify the result obtained, based on Agency theory, inasmuch as debt is used by companies with low growth opportunities in order to discipline managerial action, which is consistent with the hypothesis that debt weakens the incentive to invest in unprofitable projects.

\section{References}

1 AIVAZIAN, V.; GE, Y. \& QIU, J. (2005) “The impact of leverage on firm investment: Canadian evidence", Journal of Corporate Finance, 11: 277 291.

2 ARELlANO, M. \& BOND, S. (1991) "Some tests of specification for panel data: Monte Carlo evidence and an application to employment equations", Review of Economic Studies, 58: 277 297.

3 BLUNDELL, M. \& BOND, S. (1998) "Initial conditions and moment restrictions in dynamic panel data models", Journal of Econometrics, 87: 115-143.

4 BRUNO, G. (2005) "Approximating the bias of LSDV estimator for dynamic unbalanced panel data models", Economic Letters, 87: 361-366.

5 CHIRINKO, R. (1993) "Business fixed investment spending: Modelling strategies, empirical results and policy implications", Journal of Economic Literature, 31: 1875-1911.

6 CLEARY, S. (1999) "The relationship between firm investment and financial status", Journal of Finance, 54: 673-692.

7 DE WET, J. \& HALL, J. (2006) "An analysis of strategic performance measures of companies listed on the JSE Securities Exchange South Africa”, South African Journal of Economics and Management Sciences, 9: 57-71.

8 EISNER, R. (1963) "Investment fact and fancy", American Economic Review, 53: 237-246.

9 FAZZARI, S.; GLENN, M.; HUBBARD, R. \& BRUCE, C. (1988) "Financing constraints and corporate investment", Brookings Papers on Economic Activity, 1: 141-195.
10 FAZZARI, S. \& PETERSON, B. (1993) "Working capital and fixed investment: New evidence on financing constraints", Rand Journal of Economics, 24: 328-342.

11 GROSSMAN, S. \& HART, O. (1982) "Corporate financial structure and managerial incentives", in: McCall, J. (ed.) The Economics of Information and Uncertainty, University of Chicago Press: Chicago: 107-140.

9 HALL, R. \& JORGENSON, D. (1967) “Tax policy and investment behavior", American Economic Review, 58: 391-414.

10 HUBBARD, G.; GLEN, A. \& WHITED, T. (1995) "Internal finance and firm investment", Journal of Money Credit and Banking, 27: 683-701.

11 JENSEN, M. (1986) "Agency costs of free cashflow, corporate finance and takeovers", American Economic Review, 76: 323-329.

12 LANG, L.; OFEK, E. \& STULZ, R. (1996). "Leverage, investment, and firm growth", Journal of Financial Economics, 40: 3-29.

13 MCCONNELL, J. \& SERVAES, H. (1995) "Equity ownership and the two faces of debt", Journal of Financial Economics, 39: 131-157.

14 MODIGLIANI, F. \& MILLER, M. (1958) "The cost of capital, corporation finance and theory of investment", American Economic Review, 48: 261297.

15 MYERS, S. (1977) "The determinants of corporate borrowing", Journal of Financial Economics, 5: 147-176.

16 NAYAGER, T. \& VAN VUUREN, J. (2005) "An analysis an organisational strategy, structure and culture that supports corporate entrepreneurship in established organizations", South African Journal of Economics and Management Sciences, 8: 29-38.

17 PRETORIUS, M. \& SHAW, G. (2004) "Business plans in bank decision-making when financing new ventures in South Africa", South African Journal of Economics and Management Sciences, 7: 221-241.

18 SCHALLER, H. (1993) "Asymmetric information liquidity constraints, and Canadian investment", Canadian Journal of Economics, 26: 542-573.

19 STULZ, R. (1990) Managerial discretion an optimal financing policies, Journal of Financial Economics, 26: 3-27.

20 VERMEULEN, P. (2002) "Business fixed investment: evidence of a financial accelerator in Europe", Oxford Bulletin of Economics and Statistics, 64: 217-235.

21 ZWIEBEL, J. (1996) "Dynamic capital structure under management entrenchment", American Economic Review, 86: 1197-1215. 


\section{Appendices}

\section{Appendix A: Descriptive statistics and correlation matrix}

Table A1

Descriptive statistics

\begin{tabular}{|c|c|c|c|c|c|}
\hline Variable & Observations & Mean & $\begin{array}{c}\text { Standard } \\
\text { deviation }\end{array}$ & Minimum & Maximum \\
\hline$\frac{I_{i, t}}{K_{i, t-1}}$ & 222 & 0.013 & 0.463 & -0.800 & 3.096 \\
\hline$\frac{\text { Sales }}{K_{i, t-1}-1}$ & 222 & 1.831 & 1.482 & 0.017 & 8.194 \\
\hline$\frac{C F_{i, t}}{K_{i, t-1}}$ & 222 & 0.151 & 0.217 & -0.983 & 0.997 \\
\hline Lev $_{i, t-1}$ & 222 & 0.712 & 0.145 & 0.301 & 17.17 \\
\hline$G O P_{i, t-1}$ & 216 & 1.448 & 1.510 & 0.430 & 0.987 \\
\hline
\end{tabular}

Table A2

Correlation matrix

\begin{tabular}{|c|c|c|c|c|c|c|}
\hline & $\frac{I_{i, t}}{K_{i, t-1}}$ & $\frac{I_{i, t-1}}{K_{i, t-2}}$ & $\frac{\text {Sales}_{i, t-1}}{K_{i, t-2}}$ & $\frac{C F_{i, t}}{K_{i, t-1}}$ & Lev $_{i, t-1}$ & GOP $_{i, t-1}$ \\
\hline$\frac{I_{i, t}}{K_{i, t-1}}$ & 1 & & & & \\
\hline$\frac{I_{i, t-1}}{K_{i, t-2}}$ & $0.186^{* * *}$ & 1 & & & \\
\hline$\frac{S a l e s_{i, t-1}}{K_{i, t-2}}$ & 0.067 & $-0.168^{* * *}$ & 1 & & \\
\hline$\frac{C F_{i, t}}{K_{i, t-1}}$ & $0.312^{* * *}$ & -0.067 & $0.374^{* * *}$ & 1 & & \\
\hline Lev $_{i, t-1}$ & $-0.128^{*}$ & $-0.226^{* * *}$ & 0.033 & -0.024 & & \\
\hline GOP $_{i, t-1}$ & $0.329^{* * *}$ & 0.103 & -0.072 & $-0.193^{* * *}$ & $-0.129 *$ & 1 \\
\hline
\end{tabular}

\section{Note:}

*** indicates significance at a 1 per cent level of significance,

** indicates significance at a 5 per cent level of significance, and

* indicates significance at a 10 per cent level of significance. 


\section{Appendix B: Static panel models with investment lag}

\section{Table B1}

Static panel models: Investment lag

\begin{tabular}{|c|c|c|c|}
\hline \multicolumn{4}{|c|}{ Dependent variable: $\frac{I_{i, t}}{K_{i, t-1}}$} \\
\hline Independent variables & Pooled effects & Random effects & Fixed effects \\
\hline$\frac{I_{i, t-1}}{K_{i, t-2}}$ & $\begin{array}{c}0.0563 \\
(0.0394)\end{array}$ & $\begin{array}{c}0.0524 \\
(0.0395)\end{array}$ & $\begin{array}{c}0.0621 \\
(0.0438)\end{array}$ \\
\hline$\frac{\text { Sales }_{i, t-1}}{K_{i, t-2}}$ & $\begin{array}{l}-0.0266 \\
(0.0205)\end{array}$ & $\begin{array}{l}-0.0283 \\
(0.0200)\end{array}$ & $\begin{array}{c}0.0643 \\
(0.0556)\end{array}$ \\
\hline$\frac{C F_{i, t}}{K_{i, t-1}}$ & $\begin{array}{l}0.9040^{* * *} \\
(0.1996)\end{array}$ & $\begin{array}{l}0.9010^{* * *} \\
(0.1968)\end{array}$ & $\begin{array}{l}1.6866^{* * *} \\
(0.2494)\end{array}$ \\
\hline$L e v_{i, t-1}$ & $\begin{array}{l}-0.0988 \\
(0.1840)\end{array}$ & $\begin{array}{l}-0.0731 \\
(0.1788)\end{array}$ & $\begin{array}{l}-0.2317 \\
(0.3616)\end{array}$ \\
\hline$G O P_{i, t-1}$ & $\begin{array}{c}0.0106 \\
(0.0274)\end{array}$ & $\begin{array}{l}-0.0045 \\
(0.0274)\end{array}$ & $\begin{array}{c}0.0005 \\
(0.0306)\end{array}$ \\
\hline$D_{i, t-1} \times L e v_{i, t-1}$ & $\begin{array}{l}-0.0333 \\
(0.0774)\end{array}$ & $\begin{array}{l}-0.0244 \\
(0.0755)\end{array}$ & $\begin{array}{c}0.0980 \\
(0.0994)\end{array}$ \\
\hline CONS & $\begin{array}{l}-0.0486 \\
(0.1272)\end{array}$ & $\begin{array}{c}0.1192 \\
(0.1351)\end{array}$ & $\begin{array}{r}-0.1790 \\
(0.2532)\end{array}$ \\
\hline Observations & 178 & 178 & 178 \\
\hline $\mathrm{R}^{2}$ & 0.1579 & 0.3207 & 0.3907 \\
\hline $\mathrm{F}(\mathrm{N}(0,1))$ & $5.65^{* * *}$ & & $8.91^{* * *}$ \\
\hline Wald $\left(\chi^{2}\right)$ & & $51.13^{* * *}$ & \\
\hline LM test & & 0.25 & \\
\hline Hausman Test & & $25.09 * * *$ & \\
\hline $\mathrm{m} 1(0,1)$ & & & -0.28 \\
\hline $\mathrm{m} 2(0,1)$ & & & -0.11 \\
\hline
\end{tabular}

\section{Notes:}

1. The LM test has a $\chi^{2}$ distribution and tests the null hypothesis that non-observable individual effects are not relevant in explaining the dependent variable against the alternative hypothesis of relevance of non-observable individual effects in explaining the dependent variable.

2. The Hausman test has a $\chi^{2}$ distribution and tests the null hypothesis that non-observable individual effects are not correlated with the explanatory variables against the null hypothesis of correlation between non-observable individual effects and the explanatory variables.

3. The Wald test has a $\chi^{2}$ distribution and tests the null hypothesis of non-significance as a whole of the parameters of the explanatory variables against the alternative hypothesis of significance as a whole of the parameters of the explanatory variables. 
4. The F test has a normal distribution $\mathrm{N}(0.1)$ and tests the null hypothesis of non-significance as a whole of the estimated parameters against the alternative hypothesis of significance as a whole of the estimated parameters.

5. The $\mathrm{m} 1$ test is a test for first order autocorrelation of residuals and is distributed as $\mathrm{N}(0.1)$, under a null hypothesis of no first order autocorrelation.

6. The $\mathrm{m} 2$ test is a test for second order autocorrelation of residuals and is distributed as $\mathrm{N}(0.1)$, under a null hypothesis of no second order autocorrelation.

7. Standard deviations in brackets.

8. *** significant at a 1 per cent level of significance;

** significant at a 5 per cent level of significance;

* significant at a 10 per cent level of significance.

9. Year-dummies are included, in estimation, but are not shown. 